\title{
Quantitative Analysis of Gap Between the
} Intraocular Lens and Posterior Capsule Using Microscope-Integrated Optical Coherence Tomography in Eyes Undergoing Phacoemulsification

\author{
Ritu Nagpal \\ Chetan Shakkarwal \\ Rinky Agarwal \\ Rahul Kumar Bafna (D) \\ Prafulla Kumar Maharana \\ Namrata Sharma (D) \\ Cataract, Cornea \& Refractive Surgery \\ Services, Dr. Rajendra Prasad Centre for \\ Ophthalmic Sciences, All India Institute of \\ Medical Sciences, New Delhi, India
}

Correspondence: Namrata Sharma Cataract, Cornea \& Refractive Surgery Services, Dr. Rajendra Prasad Centre for Ophthalmic Sciences, All India Institute of Medical Sciences, New Delhi, India Tel +9l-II-26593| 44

Email namrata.sharma@gmail.com
Purpose: To quantitatively analyze the dimensions of the gap between the intraocular lens (IOL) and the posterior capsule using microscope-integrated optical coherence tomography (MIOCT).

Setting: Institutional.

Design: Prospective, interventional.

Methods: A total of 105 eyes of 105 consecutive patients planned for phacoemulsification with IOL implantation were enrolled. At the end of surgery, the gap between the IOL and the posterior capsule (IOL-PC gap) was measured using MIOCT (RESCAN). The same gap was reassessed at 1 week follow-up visit using the Visante-OCT system. The cases were subgrouped based on the grade of cataract, IOL material, size and design and were analyzed to look for any difference in the IOL-PC gap both intraoperatively and postoperatively.

Results: The IOL-PC gap could be successfully measured intra-operatively in all cases, using the RESCAN. The mean gap at the end of phacoemulsification was $385.08 \pm 264.58$ $\mu \mathrm{m}$, and at one week follow up this was $120.83 \pm 95.13 \mu \mathrm{m}$.

Conclusion: MIOCT may be successfully used to quantify the dimensions of the gap between the IOL and the posterior capsule. It can be used as a potential tool to further understand the dynamics of the IOL-PC space and to assess the impact of various IOL and non-IOL parameters implicated in the causation of posterior capsule opacification.

Keywords: cataract surgery, intraocular lens-posterior capsule gap, microscope-integrated optical coherence tomography, spectral domain optical coherence tomography, RESCAN

\section{Introduction}

The field of cataract surgery has witnessed a lot of developments in the past decade, related to advancements in the surgical equipment and technique and the introduction of new models and designs of intraocular lenses (IOL). Despite these advancements, cataract surgeons still have to deal with the problem of posterior capsule opacification, which, if significant, compromises the functional outcome of surgery. This is especially true for premium IOL implantation, where precise IOL positioning is vital. The gap between the IOL and the posterior capsule is a potential space for the proliferated anterior lens epithelial cells to migrate and 
cause formation of proliferative type posterior capsule opacification (PCO). Various studies have focused on targeting the factors which help to limit this cellular migration, thereby reducing PCO formation. These include IOL-related factors such changes in the IOL optic design (square optic edges) to create a barrier effect, mechanical compression of the capsular bag by implanting large-size IOLs and use of expanding rings to maintain capsular bag contour and enhance endocapsular circulation of aqueous humor. ${ }^{1-5}$ Another important aspect related to the IOL-PC space is its bearing on postoperative refractive status of the eye.

Intraoperative optical coherence tomography (OCT) is a newer modality which is increasingly gaining acceptance by both anterior and posterior segment surgeons. This is due to the provision of real-time visualization of various intraocular structures and anatomic planes during surgery. It also helps in confirming and managing various intraoperative complications. ${ }^{6}$ In 2005, Geerling et al first described the use of an intraoperative OCT system, subsequent to which several innovations have been made to effectively utilize this system. ${ }^{7}$

Currently, there are three commercial microscopeintegrated optical coherence tomography systems (MIOCT), which are Food and Drug Administration approved: the Haag-Streit OCT-system (Haag-Streit, Koeniz, Switzerland), the Zeiss platform Rescan 700 (Zeiss, Oberkochen, Germany) and the Leica EnFocus system (Leica, Wetzlar, Germany). ${ }^{6,8}$

Applications of MIOCT are gaining popularity in the field of cataract surgery as well. ${ }^{9,10}$ It is able to provide real-time information related to wound architecture, status of Descemet's membrane, lenticular details, status of posterior capsule and position of the IOL with respect to the posterior capsule. In this study we evaluated the usefulness of MIOCT to quantitatively analyze the dimensions of the IOL-PC space in eyes undergoing routine phacoemulsification.

\section{Patients and Methods}

This prospective study was conducted at the Dr. Rajendra Prasad Centre for Ophthalmic Sciences, AIIMS, New Delhi, India. All cases of senile cataract planned for phacoemulsification with IOL implantation from June 2019 to July 2020 were enrolled. Ethics approval was obtained from the ethics committee of All India Institute of Medical Sciences, New Delhi, India. A written and informed consent was obtained from all patients. The study was performed according to the tenets of the Declaration of Helsinki.

Exclusion criteria for the study were eyes with anterior capsular wrinkling or calcification, presence of intumescent cataract, lenticular subluxation, posterior polar cataract, pseudoexfoliation syndrome, history of previous ocular trauma and intraoperative floppy iris syndrome.

At baseline demographic features including the age and gender of all patients were noted. Partial coherence interferometry was performed using IOL master 500 (Carl Zeiss Meditec AG) to calculate spherical IOL power.

\section{Surgical Technique}

All surgeries were performed by a single surgeon (NS) under topical anesthesia using the CENTURION Vision System. The active fluidics technology of this system helps to maintain the preset IOP based on the flow rate, irrigation pressure and vacuum, at all stages of surgery.

Temporal self-sealing clear corneal incision measuring $2.2 \mathrm{~mm}$ was used as the main port, and 2 paracentesis incisions were created at 7 and 11 o'clock positions. Anterior chamber was expanded using a viscocohesive ( $1 \%$ sodium hyaluronate) viscoelastic (HEALON, Abbott Medical Optics; Mumbai, India), and a capsulorrhexis measuring $4.5-5.5 \mathrm{~mm}$ in size was created to ensure adequate overlap with the IOL optic. Following hydrodissection and hydrodelineation, nuclear emulsification was performed. After ensuring complete viscoelastic removal, the IOL was implanted within the capsular bag. Postoperatively, all patients were prescribed topical antibiotics (eye drop moxifloxacin 0.5\%; Vigamox; Alcon, Fort Worth, Texas) and anti-inflammatory medications in tapering doses (eye drop 1\% prednisolone phosphate; Pred Forte; Allergan, Dublin, Ireland).

\section{Intraoperative OCT Imaging}

An operating microscope integrated with OCT system (OPMI LUMERA 700 and RESCAN 700; Carl Zeiss, Jena, Germany) was used to measure the distance between the IOL and the posterior capsule. This is a spectral domain OCT, which works at a wavelength of $840 \mathrm{~nm}$. It acquires 27,000 A-scans per second, with an axial resolution of $5.5 \mu \mathrm{m}$ and an A-scan depth of $2000 \mu \mathrm{m}$.

The OCT does not have measuring calipers to allow for direct measurement from the screen. The measurements were obtained by a method reported in a study published earlier from our center. ${ }^{11} \mathrm{~A}$ 9-mm cube was acquired for analysis. From the OCT scan displayed on the screen, 
a ruler was used to measure the distance between the posterior capsule and the IOL. Measured readings in millimeters were converted into microns.

\section{Postoperative Analysis}

At postoperative 1 week, the IOL-PC gap was reassessed using the Visante-OCT system (Carl Zeiss Meditec Inc, Dublin, CA, USA). Cases were sub-grouped based on the grade of cataract, as documented pre-operatively, and the material, size and design of the IOL implanted in the capsular bag (Figure 1). The IOL-PC gap measured intraoperatively using MIOCT and postoperatively, using the ASOCT system, was compared between various sub-groups.

\section{Statistical Analysis}

Statistical analysis was done using STATA version 12.1. Mean values, standard deviations and frequency (\%) distributions were calculated for each parameter. Intergroup comparisons were done using the Wilcoxon signed rank test. Results were considered statistically significant if $p$ value was less than 0.05 .

\section{A. Grades of cataract}

1 Nuclear sclerosis grade 1

2 Nuclear sclerosis grade 2,early central posterior sub-capsular cataract

3 Nuclear sclerosis grade 3, dense posterior sub-capsular cataract

4 Nuclear sclerosis grade 4

5 Hypermature cataract, white cataract, total cataract

1 Tecnis $1 \mathrm{ZCB} 00$

\section{B. IOL type}

2 Acrosof IQ; SN60WF

3 Zeiss CT LUCIA611P/PY

4 Supraphob toric

5 CARE ACRIOL

6 EYECRYL PLUS CLEAR

111

211.25

312

412.5

$5 \quad 13$

1 C-type

D. Haptic design

2 Plate haptic

Figure I Classification of various sub-groups.

\section{Results}

A total of 105 eyes of 105 patients undergoing cataract surgery and IOL implantation were analyzed. Mean age of patients was $61.3 \pm 11.32$ years; $53 \%(n=56)$ were males, and $47 \%(n=49)$ were females.

The IOL-PC gap could be successfully measured in all cases using MIOCT. The mean IOL-PC gap at the end of the procedure was $385.08 \pm 264.58$ microns, and one week following surgery it was $120.83 \pm 95.13$ microns. No significant difference was seen in the IOL-PC gap either at the end of the surgery or at one week following surgery, among various sub-groups. The baseline parameters and comparison between different sub-groups has been summarized in Table 1.

\section{Discussion}

MIOCT has been used for various purposes in cataract surgery such as identification of a pre-existing PC defect, grading and classification of posterior polar cataract, evaluation of wound configuration and diagnosis and management of complications such as Descemet's membrane detachment. $^{12-17}$ MIOCT is an extremely useful tool since it is able to provide real-time visualization of various intraoperative events.

Interactions between the IOL and the capsular bag have always been of interest to cataract surgeons, owing to their role in the pathogenesis of PCO formation. Over the time, various tools have been explored to study the dynamics of the IOL-PC space. Scheimpflug imaging ${ }^{18}$ and ultrasound biomicroscopy ${ }^{19}$ have been used and evaluated in the past with variable success rates. These tools, although allowing the surgeons to visualize the IOL-PC space, lack a quantitative measuring tool.

Tao et al evaluated the role of a custom-built highresolution OCT for quantitative characterization of the IOL-PC space in the early postoperative period, in a randomized study including 30 eyes. ${ }^{10}$ Using custombuilt software (J-OCT-1), the boundaries of the IOL and the posterior capsule were identified, and the meridional area of the IOL-PC space was measured. The authors could successfully quantify the IOL-PC space in all of their cases. Besides quantifying, they were also able to compare the dynamics of this space among different types of IOL sub-groups. ${ }^{10}$ Lytvynchuk et al, $^{20}$ in a prospective study involving 101 eyes, evaluated the position of the IOL at the end of phacoemulsification using an intraoperative spectral domain OCT system 
Table I Baseline Characteristics and Comparison of Mean Gap Between the Posterior Surface of the Intraocular Lens and the Posterior Capsule, as Measured Intra-Operatively by MIOCT and Postoperatively by Anterior Segment OCT

\begin{tabular}{|c|c|c|c|c|c|c|c|c|c|c|c|}
\hline Parameters & Sub-Groups & $\mathbf{N}$ & $\%$ & Mean & SD & $\begin{array}{l}\text { Mean IOL- } \\
\text { PC Gap } \\
\text { (MIOCT) }\end{array}$ & SD & $\begin{array}{l}\text { Mean IOL- } \\
\text { PC Gap } \\
\text { (ASOCT) }\end{array}$ & SD & $\begin{array}{c}\text { Inter-Group } \\
\text { Difference } \\
\text { (MIOCT) }\end{array}$ & $\begin{array}{c}\text { Inter-Group } \\
\text { Difference } \\
\text { (ASOCT) }\end{array}$ \\
\hline Age & & 105 & & 61.3 & 11.32 & & & & & & \\
\hline \multirow[t]{2}{*}{ Gender } & $M$ & 56 & 53 & & & & & & & & \\
\hline & $\mathrm{F}$ & 49 & 47 & & & & & & & & \\
\hline \multirow{5}{*}{$\begin{array}{l}\text { Cataract } \\
\text { Grade }\end{array}$} & I (NS I) & 10 & 9.5 & & & 325.5 & |68.7| & 110.2 & 50.50 & 0.49 & 0.78 \\
\hline & $\begin{array}{c}2 \text { (NS 2, early } \\
\text { central PSC) }\end{array}$ & 49 & 46.6 & & & 421.84 & 300.36 & $135.6 \mid$ & 117.33 & & \\
\hline & $\begin{array}{c}3 \text { (NS 3, dense } \\
\text { central PSC) }\end{array}$ & 27 & 25.7 & & & 391 & 253.18 & 103.629 & 74.64 & & \\
\hline & 4 (NS 4) & 10 & 9.5 & & & 254.4 & 155.15 & 92.8 & 49.12 & & \\
\hline & $\begin{array}{c}5 \text { (HMC, WC, } \\
\mathrm{TC})\end{array}$ & 9 & 8.5 & & & 378.55 & 258.97 & 135 & 87.66 & & \\
\hline \multirow[t]{2}{*}{ Haptic Design } & I (C type) & 101 & 96.19 & & & 376.94 & 259.03 & 118.16 & 93.74 & 0.42 & 0.66 \\
\hline & 2 (Plate haptic) & 4 & 3.81 & & & 590.62 & 362.76 & 188.25 & 120.59 & & \\
\hline \multirow[t]{6}{*}{ IOL Type } & I (Tecnis) & 32 & 30.47 & & & 399.20 & 237.68 & $|20.7|$ & 73.39 & 0.55 & 0.61 \\
\hline & 2 (Acrysof IQ) & 56 & 53.33 & & & 387.70 & 280.95 & 127.80 & 108.42 & & \\
\hline & $\begin{array}{c}3 \text { (Zeiss CT } \\
\text { LUCIA) }\end{array}$ & 3 & 2.85 & & & 487.5 & 496.07 & 126.66 & $|75.9|$ & & \\
\hline & $\begin{array}{c}4 \text { (Supraphob } \\
\text { Toric) }\end{array}$ & 2 & 1.90 & & & 525 & 212.13 & 100.5 & 84.14 & & \\
\hline & $\begin{array}{l}5 \text { (CARE } \\
\text { ACRIOL) }\end{array}$ & 10 & 9.52 & & & 307.5 & 217.80 & 89.4 & 69.06 & & \\
\hline & $\begin{array}{c}6 \\
\text { (EYECRYLPLUS } \\
\text { CLEAR) }\end{array}$ & 2 & 1.90 & & & 180 & 42.42 & 96.5 & 33.23 & & \\
\hline \multirow[t]{5}{*}{ IOL Size (mm) } & I (II) & 2 & 1.90 & & & 581.25 & 662.91 & 208 & 171.11 & 0.59 & 0.76 \\
\hline & $2(11.25)$ & 2 & 1.90 & & & 506.25 & 291.68 & 191.5 & 45.96 & & \\
\hline & $3(12)$ & 3 & 2.85 & & & 525 & 456.20 & 99 & 47.50 & & \\
\hline & $4(12.5)$ & 4 & 3.80 & & & 346.87 & 215.14 & 42.75 & 39.44 & & \\
\hline & $5(13)$ & 94 & 89.52 & & & 375.48 & 254.44 & 121.5 & 95.58 & & \\
\hline
\end{tabular}

Abbreviations: N, number of patients; SD, standard deviation; MIOCT, microscope-integrated optical coherence tomography; ASOCT, anterior segment optical coherence tomography; IOL, intraocular lens; PC, posterior capsule; M, male; F, female; NS, nuclear sclerosis; PSC, posterior subcapsular cataract; HCM, hypermature cataract; WC, white cataract; TC, total cataract.

(RESCAN 700). The study concluded that the use of an intraoperative OCT system facilitates IOL imaging in terms of assessment of its position with respect to both the anterior and the posterior capsule.
In the current study, we evaluated the feasibility of a commercially available MIOCT system (RESCAN) to quantify the IOL-PC space. We could successfully measure the IOL-PC gap in all our cases. Although it was not our primary 
goal, we further compared the IOL-PC space between different groups based on pre-operative cataract grade and the type and size of the design of the implanted IOL. We did not find any significant influence of these factors on the dimensions of the IOL-PC gap. However, considering the lack of randomization for allocation of subjects in various sub-groups, a high standard deviation and a variable number of patients in different sub-groups, we believe the results may not reflect the true impact of these factors on the IOL-PC gap and its dynamics in the postoperative period. A randomized and homogeneous study would be desired to exactly estimate the effect of various IOL-related parameters on this space.

To conclude, MIOCT can be successfully used to study the dynamics of the IOL-PC space during cataract surgery. The biggest advantage of this method over other available tools is that it provides the surgeon with a quantitative tool to exactly measure this space. Further large, randomized studies using the MIOCT system will definitely help in better understanding of the dynamics of the IOL-PC space.

\section{Disclosure}

The authors report no funding or conflicts of interest for this work.

\section{References}

1. Nishi O, Nishi K, Menapace R. Capsule-bending ring for the prevention of capsular opacification: a preliminary report. Ophthalmic Surg Lasers. 1998;29:749-753.

2. Alon R, Assia EI, Kleinmann G. Prevention of posterior capsule opacification by an intracapsular open capsule device. Invest Ophthalmol Vis Sci. 2014;55(7):4005-4013. doi:10.1167/iovs. 14-14364

3. Nishi O, Yamamoto N, Nishi K, Nishi Y. Contact inhibition of migrating lens epithelial cells at the capsular bend created by a sharp-edged intraocular lens after cataract surgery. J Cataract Refract Surg. 2007;33(6):1065-1070. doi:10.1016/j.jcrs.2007.02.022

4. Nishi O, Nishi K, Sakanishi K. Inhibition of migrating lens epithelial cells at the capsular bend created by the rectangular optic edge of a posterior chamber intraocular lens. Ophthalmic Surg Lasers. 1998;29 (7):587-594.

5. Nagamoto T, Fujiwara T. Inhibition of lens epithelial cell migration at the intraocular lens optic edge; role of capsule bending and contact pressure. $J$ Cataract Refract Surg. 2003;29(8):1605-1612. doi:10.1016/S0886-3350(03)00050-6

6. Das S, Kummelil MK, Kharbanda V, et al. Microscope integrated intraoperative spectral domain optical coherence tomography for cataract surgery: uses and applications. Curr Eye Res. 2016;41 (5):643-652. doi:10.3109/02713683.2015.1050742

7. Geerling G, Müller M, Winter C, et al. Intraoperative 2-dimensional optical coherence tomography as a new tool for anterior segment surgery. Arch Ophthalmol. 2005;123:253-257. doi:10.1001/ archopht.123.2.253
8. Carrasco-Zevallos OM, Viehland C, Keller B, et al. Review of intraoperative optical coherence tomography: technology and applications [Invited]. Biomed Opt Express. 2017;8:1607-1637. doi:10.1364/BOE.8.001607

9. Posarelli C, Sartini F, Casini G, et al. What is the impact of intraoperative microscope-integrated OCT in ophthalmic surgery? Relevant applications and outcomes. a systematic review. J Clin Med. 2020;9 (6): 1682 . doi: $10.3390 / \mathrm{jcm} 9061682$

10. Tao A, Lu P, Li J, et al. High resolution OCT quantitative analysis of the space between the IOL and the posterior capsule during the early cataract postoperative period. Invest Ophthalmol Vis Sci. 2013;54 (10):6991-6997. doi:10.1167/iovs.13-12849

11. Titiyal JS, Kaur M, Sahu S, Sharma N, Sinha R. Real-time assessment of intraoperative vaulting in implantable collamer lens and correlation with postoperative vaulting. Eur J Ophthalmol. 2017;27 (1):21-25. doi:10.5301/ejo.5000818

12. Kymionis GD, Diakonis VF, Liakopoulos DA, Tsoulnaras KI, Klados NE, Pallikaris IG. Anterior segment optical coherence tomography for demonstrating posterior capsular rent in posterior polar cataract. Clin Ophthalmol. 2014;8:215-217. doi:10.2147/OPTH. S55763

13. Chan TCY, Li EYM, Yau JCY. Application of anterior segment optical coherence tomography to identify eyes with posterior polar cataract at high risk for posterior capsule rupture. $J$ Cataract Refract Surg. 2014;40:2076-2081. doi:10.1016/j.jcrs.2014.03.033

14. Pavan Kumar G, Krishnamurthy P, Nath M, Baskaran P, Janani M, Venkatesh R. Can preoperative anterior segment optical coherence tomography predict posterior capsule rupture during phacoemulsification in patients with posterior polar cataract? J Cataract Refract Surg. 2018;44(12):1441-1445. doi:10.1016/j.jcrs.2018.07.056

15. Amir-Asgari S, Hirnschall N, Findl O. Using continuous intraoperative optical coherence tomography to classify swirling lens fragments during cataract surgery and to predict their impact on corneal endothelial cell damage. $J$ Cataract Refract Surg. 2016;42 (7):1029-1036. doi:10.1016/j.jcrs.2016.04.029

16. Hirnschall N, Farrokhi S, Amir-Asgari S, Hienert J, Findl O. Intraoperative optical coherence tomography measurements of aphakic eyes to predict postoperative position of 2 intraocular lens designs. $J$ Cataract Refract Surg. 2018;44(11):1310-1316. doi:10.1016/j.jcrs.2018.07.044

17. Titiyal JS, Kaur M, Shaikh F, Goel S, Bageshwar LMS. Real-time intraoperative dynamics of white cataract-intraoperative optical coherence tomography-guided classification and management. $J$ Cataract Refract Surg. 2020;46(4):598-605. doi:10.1097/j. jcrs.0000000000000086

18. Hayashi H, Hayashi K, Nakao F, Hayashi F. Elapsed time for capsular apposition to intraocular lens after cataract surgery. Ophthalmology. 2002;109(8):1427-1431. doi:10.1016/S01616420(02)01112-0

19. García-Feijoó J, Hernández-Matamoros JL, Méndez-Hernández C, et al. Ultrasound biomicroscopy of silicone posterior chamber phakic intraocular lens for myopia. $J$ Cataract Refract Surg. 2003;29:1932-1939. doi:10.1016/S0886-3350(03)00239-6

20. Lytvynchuk LM, Glittenberg CG, Falkner-Radler CI, et al. Evaluation of intraocular lens position during phacoemulsification using intraoperative spectral-domain optical coherence tomography. $J$ Cataract Refract Surg. 2016;42(5):694-702. doi:10.1016/j. jcrs.2016.01.044 


\section{Publish your work in this journal}

Clinical Ophthalmology is an international, peer-reviewed journal covering all subspecialties within ophthalmology. Key topics include: Optometry; Visual science; Pharmacology and drug therapy in eye diseases; Basic Sciences; Primary and Secondary eye care; Patient Safety and Quality of Care Improvements. This journal is indexed on PubMed

Submit your manuscript here: https://www.dovepress.com/clinical-ophthalmology-journal
Central and CAS, and is the official journal of The Society of Clinical Ophthalmology (SCO). The manuscript management system is completely online and includes a very quick and fair peer-review system, which is all easy to use. Visit http://www.dovepress.com/ testimonials.php to read real quotes from published authors. 